\title{
Canagliflozin improves risk factors of metabolic syndrome in patients with type 2 diabetes mellitus and metabolic syndrome
}

This article was published in the following Dove Press journal: Diabetes, Metabolic Syndrome and Obesity:Targets and Therapy 27 January 2017

Number of times this article has been viewed

\author{
Michael J Davies' \\ Katherine W Merton' \\ Ujjwala Vijapurkar ${ }^{2}$ \\ Dainius A Balis ${ }^{2}$ \\ Mehul Desai ${ }^{2}$ \\ 'Janssen Scientific Affairs, LLC, \\ Titusville, NJ, USA; ${ }^{2}$ Janssen Research \\ \& Development, LLC, Raritan, NJ, USA
}

Correspondence: Michael J Davies Janssen Scientific Affairs, LLC, II 25 Trenton-Harbourton Road, Titusville, NJ 08560, USA

Tel +l 6097306288

Email mdavies9@its.jnj.com
Objective: Metabolic syndrome refers to a collection of risk factors associated with the development of cardiovascular disease and type 2 diabetes mellitus (T2DM). Canagliflozin, a sodium glucose co-transporter 2 inhibitor, improves glycemic control and reduces body weight and blood pressure (BP) in a broad range of patients with T2DM. This post hoc analysis assessed the effects of canagliflozin on the components of metabolic syndrome in patients with T2DM and metabolic syndrome.

Methods: This analysis was based on data from 2 head-to-head studies of canagliflozin in patients with T2DM on background metformin versus glimepiride (study 1) and background metformin plus sulfonylurea versus sitagliptin $100 \mathrm{mg}$ (study 2). Changes from baseline in glycemic efficacy, anthropometric measures, BP, and lipids were evaluated with canagliflozin versus glimepiride and sitagliptin at week 52 in patients who met $\geq 2$ of the criteria for metabolic syndrome (in addition to T2DM): triglycerides $\geq 1.7 \mathrm{mmol} / \mathrm{L}$; high-density lipoprotein cholesterol (HDL-C) $<1.0 \mathrm{mmol} / \mathrm{L}$ (men) or $<1.3 \mathrm{mmol} / \mathrm{L}$ (women); waist circumference $\geq 102 \mathrm{~cm}$ (nonAsian men), $\geq 88 \mathrm{~cm}$ (non-Asian women), $>90 \mathrm{~cm}$ (Asian men), or $>80 \mathrm{~cm}$ (Asian women); diagnosis of hypertension or meeting BP-related criteria (systolic $\mathrm{BP} \geq 130 \mathrm{mmHg}$ or diastolic BP $\geq 85 \mathrm{mmHg}$ ). Safety was assessed based on adverse event reports.

Results: In study 1, canagliflozin 100 and $300 \mathrm{mg}$ provided similar and greater $\mathrm{HbA} 1 \mathrm{c}$ reductions versus glimepiride, respectively. In study 2, canagliflozin $300 \mathrm{mg}$ provided greater $\mathrm{HbA} 1 \mathrm{c}$ lowering versus sitagliptin $100 \mathrm{mg}$. Canagliflozin also reduced fasting plasma glucose, body weight, body mass index, waist circumference, BP, and triglycerides, and increased HDL-C and low-density lipoprotein cholesterol versus glimepiride and sitagliptin. Canagliflozin was generally well tolerated in each study.

Conclusion: Canagliflozin was associated with improvements in all components of metabolic syndrome in patients with T2DM and metabolic syndrome, whereas glimepiride and sitagliptin only improved glycemic components over 52 weeks.

Keywords: canagliflozin, sodium glucose co-transporter 2, type 2 diabetes, metabolic syndrome

\section{Introduction}

Metabolic syndrome refers to a collection of risk factors associated with the development of cardiometabolic complications and type 2 diabetes mellitus (T2DM). ${ }^{1}$ Criteria for the metabolic syndrome can vary, but typically include dyslipidemia (ie, increased triglycerides, reduced high-density lipoprotein cholesterol [HDL-C]), central obesity, hypertension, and glucose intolerance. ${ }^{1,2}$ In the United States, the prevalence of metabolic syndrome has been estimated to be nearly $35 \%$ in adults, with a higher prevalence $(\sim 50 \%)$ in those aged $\geq 60$ years. ${ }^{3}$ Metabolic syndrome is also prevalent in Europe, 
affecting an estimated $\sim 40 \%-80 \%$ of men and $\sim 25 \%-65 \%$ of women, depending on criteria, age, and geographic region. ${ }^{4}$

Canagliflozin, a sodium glucose co-transporter 2 (SGLT2) inhibitor, increases urinary glucose excretion, leading to decreased plasma glucose levels and a net caloric loss in patients with T2DM. ${ }^{5}$ Across phase 3 studies, canagliflozin improved glycemic control, body weight, and blood pressure (BP), and was generally well tolerated in a broad range of patients with T2DM. ${ }^{6-23}$ In head-to-head trials, canagliflozin $300 \mathrm{mg}$ demonstrated superiority in HbA1c lowering versus glimepiride as add-on to metformin ${ }^{20}$ and versus sitagliptin $100 \mathrm{mg}$ as add-on to metformin or metformin plus sulfonylurea at 52 weeks. ${ }^{8,22}$ Canagliflozin also provided statistically significant reductions in body weight and BP compared with glimepiride and sitagliptin. ${ }^{8,20,22}$ The improvements in HbA1c, body weight, and BP seen with canagliflozin suggest that it may be an effective treatment for improving the components of metabolic syndrome in patients with T2DM. The present analysis evaluated the effects of canagliflozin versus glimepiride and sitagliptin in patients with T2DM and metabolic syndrome.

\section{Methods}

\section{Study design and patient populations}

This post hoc analysis was based on data from 2 randomized, double-blind, head-to-head, phase 3 studies that evaluated the efficacy and safety of canagliflozin in patients with T2DM. In study 1 (ClinicalTrials.gov identifier: NCT00968812), patients $(\mathrm{N}=1,450)$ received canagliflozin 100 or $300 \mathrm{mg}$ or glimepiride as add-on to metformin for a 52-week core treatment period, followed by a 52-week extension period; ${ }^{20,21}$ the current analysis was based on data from the 52-week core treatment period. In study 2 (ClinicalTrials.gov identifier: NCT01137812), patients $(\mathrm{N}=755)$ received canagliflozin $300 \mathrm{mg}$ or sitagliptin 100 $\mathrm{mg}$ as add-on to metformin plus sulfonylurea for a 52-week core treatment period. ${ }^{22}$ Details of the individual study designs and results have been published previously. ${ }^{20,22}$

The effects of canagliflozin versus glimepiride and sitagliptin on the components of metabolic syndrome were assessed in the subset of patients from each study who met $\geq 2$ of the following criteria for metabolic syndrome (in addition to T2DM); ${ }^{1,2}$ triglycerides $\geq 1.7 \mathrm{mmol} / \mathrm{L}$; HDL-C $<1.0 \mathrm{mmol} / \mathrm{L}$ in men or $<1.3 \mathrm{mmol} / \mathrm{L}$ in women; waist circumference $\geq 102 \mathrm{~cm}$ (non-Asian men), $\geq 88 \mathrm{~cm}$ (non-Asian women), >90 cm (Asian men), or >80 cm (Asian women); diagnosis of hypertension or meeting BP-related criteria (systolic $\mathrm{BP} \geq 130 \mathrm{mmHg}$ or diastolic $\mathrm{BP} \geq 85 \mathrm{mmHg}$ ).
The studies included in this analysis were conducted in accordance with the ethical principles outlined in the Declaration of Helsinki and followed Good Clinical Practice and applicable regulatory requirements. Approval was obtained from institutional review boards and independent ethics committees for each participating center. Participants provided informed written consent prior to enrollment in the studies.

\section{Endpoints/assessments}

Changes from baseline in glycemic parameters (HbAlc and fasting plasma glucose [FPG]), anthropometric parameters (body weight, body mass index [BMI], and waist circumference), BP (systolic and diastolic), and lipids (low-density lipoprotein cholesterol [LDL-C], HDL-C, and triglycerides) were assessed at week 52. Safety and tolerability were assessed based on adverse event (AE) reports in the overall population of each study (not the subset of patients with metabolic syndrome), as the majority of patients in each study had metabolic syndrome.

\section{Statistical analyses}

Data were from the modified intent-to-treat (mITT) population, which consisted of all randomized patients who received $\geq 1$ dose of study drug. The last observation carried forward (LOCF) approach was used to impute missing data. Efficacy endpoints were analyzed using an analysis of covariance model, with treatment, stratification factor, and frequently sampled mixed-meal tolerance test (study 2 only) as fixed effects and the corresponding baseline value as a covariate. Least squares mean differences and 2 -sided 95\% confidence intervals were estimated for the comparisons of canagliflozin versus glimepiride or sitagliptin. Statistical comparison of canagliflozin versus glimepiride or sitagliptin was not prespecified for these post hoc analyses; therefore, $P$ values are not reported.

\section{Results \\ Patients}

At baseline, $81 \%(n=1,169)$ of 1,450 randomized patients with T2DM in study 1 and $78 \%(n=586)$ of the 755 randomized patients with T2DM in study 2 met the criteria for metabolic syndrome; proportions were similar across treatment groups in each study (study 1: $82 \%, 82 \%$, and $79 \%$ with canagliflozin 100 and $300 \mathrm{mg}$ and glimepiride, respectively; study $2: 77 \%$ and $79 \%$ with canagliflozin $300 \mathrm{mg}$ and sitagliptin $100 \mathrm{mg}$, respectively). Baseline demographic characteristics were generally balanced across 
Table I Baseline demographic characteristics of patients who met the criteria for metabolic syndrome

\begin{tabular}{|c|c|c|c|c|c|}
\hline \multirow[t]{2}{*}{ Characteristics } & \multicolumn{3}{|l|}{ Study I } & \multicolumn{2}{|l|}{ Study 2} \\
\hline & $\begin{array}{l}\text { GLIM } \\
(n=379)\end{array}$ & $\begin{array}{l}\text { CANA } 100 \mathrm{mg} \\
(\mathrm{n}=394)\end{array}$ & $\begin{array}{l}\text { CANA } 300 \mathrm{mg} \\
(\mathrm{n}=396)\end{array}$ & $\begin{array}{l}\text { SITA } 100 \mathrm{mg} \\
(\mathrm{n}=297)\end{array}$ & $\begin{array}{l}\text { CANA } 300 \mathrm{mg} \\
(\mathrm{n}=289)\end{array}$ \\
\hline Mean (SD) age, year & 56.1 (8.9) & $56.3(9.5)$ & $55.9(9.4)$ & $56.6(8.7)$ & $56.9(9.9)$ \\
\hline \multicolumn{6}{|l|}{ Sex, n (\%) } \\
\hline Male & $182(48)$ & $199(5 \mathrm{I})$ & $187(47)$ & $165(56)$ & $150(52)$ \\
\hline Female & $197(52)$ & $195(50)$ & $209(53)$ & $132(44)$ & $139(48)$ \\
\hline \multicolumn{6}{|l|}{ Race, n (\%) } \\
\hline White & $266(70)$ & $277(70)$ & $283(72)$ & $199(67)$ & $196(68)$ \\
\hline Black or African American & $18(5)$ & $17(4)$ & $13(3)$ & $32(\mathrm{II})$ & $26(9)$ \\
\hline Asian & $60(16)$ & $69(18)$ & $72(18)$ & $45(15)$ & $50(17)$ \\
\hline Other ${ }^{\mathrm{b}}$ & $35(9)$ & $31(8)$ & $28(7)$ & $21(7)$ & $17(6)$ \\
\hline \multicolumn{6}{|l|}{ Ethnicity, n (\%) } \\
\hline Hispanic/Latino & $61(16)$ & $63(16)$ & $54(14)$ & $56(19)$ & $60(21)$ \\
\hline Not Hispanic/Latino & $316(83)$ & $329(84)$ & $34 I(86)$ & $240(81)$ & $229(79)$ \\
\hline Other ${ }^{c}$ & $2(0.5)$ & $2(0.5)$ & I $(0.3)$ & I $(0.3)$ & 0 \\
\hline
\end{tabular}

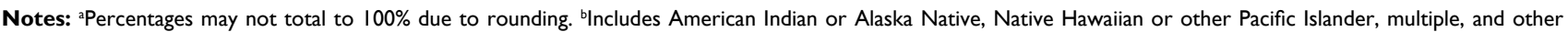
(study I) and American Indian or Alaska Native, Native Hawaiian or other Pacific Islander, multiple, other, unknown, and not reported (study 2). Includes not reported and unknown.

Abbreviations: CANA, canagliflozin; GLIM, glimepiride; SD, standard deviation; SITA, sitagliptin.

groups in the subset of patients with metabolic syndrome in each study (Table 1).

\section{Efficacy}

In study 1 , canagliflozin 100 and $300 \mathrm{mg}$ were associated with similar and greater reductions in $\mathrm{HbAlc}$, respectively, and greater reductions in FPG compared with glimepiride at week 52 (Figure 1A). Relative to glimepiride, canagliflozin 100 and $300 \mathrm{mg}$ also provided greater reductions in body weight, BMI, and waist circumference (Figure 2A), and systolic BP and diastolic BP (Figure 3A). Canagliflozin 100 and $300 \mathrm{mg}$ were associated with larger increases in HDL-C and LDL-C versus glimepiride at 52 weeks; numeric reductions in triglycerides were seen with canagliflozin 100 and $300 \mathrm{mg}$ relative to glimepiride (Figure 4A). After 52 weeks, the proportion of patients who met the criteria for metabolic syndrome diagnosis was $87 \%, 86 \%$, and $93 \%$ in the canagliflozin $100 \mathrm{mg}$, canagliflozin $300 \mathrm{mg}$, and glimepiride groups, respectively.

In study 2, canagliflozin $300 \mathrm{mg}$ provided greater reductions in $\mathrm{HbAlc}$ and FPG versus sitagliptin $100 \mathrm{mg}$ at 52 weeks (Figure 1B). Treatment with canagliflozin $300 \mathrm{mg}$ versus sitagliptin $100 \mathrm{mg}$ was also associated with greater reductions in body weight, $\mathrm{BMI}$, and waist circumference (Figure 2B), and systolic BP and diastolic BP (Figure 3B). Increases in HDL-C and LDL-C and reductions in triglycerides were seen with canagliflozin $300 \mathrm{mg}$ versus sitagliptin $100 \mathrm{mg}$ (Figure 4B). The proportion of patients who met the criteria for metabolic syndrome at 52 weeks was $89 \%$ in the canagliflozin $300 \mathrm{mg}$ group and $95 \%$ in the sitagliptin $100 \mathrm{mg}$ group.

\section{Safety}

As the proportion of patients with metabolic syndrome was nearly $80 \%$ in each study, safety was assessed in the overall population of each study rather than in the subset of patients with metabolic syndrome. Canagliflozin was generally well tolerated in both studies, with a higher incidence of AEs related to the mechanism of SGLT2 inhibition (eg, genital mycotic infections, osmotic diuresis-related AEs). ${ }^{20,22}$ In study 1 , the overall incidence of AEs was $64.4 \%, 68.5 \%$, and $68.5 \%$ with canagliflozin 100 and $300 \mathrm{mg}$ and glimepiride, respectively, at week $52 .{ }^{20}$ Incidences of genital mycotic infections (male: $6.7 \%$ and $8.3 \%$ vs $1.1 \%$; female: $11.3 \%$ and $13.9 \%$ vs $2.3 \%$ ), urinary tract infections $(6.4 \%$ and $6.4 \%$ vs $4.6 \%$ ), and osmotic diuresis-related AEs (5.6\% and 6.2\% vs $1.7 \%$ ) were higher with canagliflozin 100 and $300 \mathrm{mg}$ compared with glimepiride..$^{20,24}$ In addition, the incidence of documented hypoglycemia was significantly lower with canagliflozin 100 and $300 \mathrm{mg}$ versus glimepiride (5.6\% and $4.9 \%$ vs $34.2 \%) .{ }^{20}$

In study 2, the overall incidence of AEs was $76.7 \%$ and $77.5 \%$ with canagliflozin $300 \mathrm{mg}$ and sitagliptin $100 \mathrm{mg}$, respectively. ${ }^{22}$ Incidences of genital mycotic infections (male: $9.2 \%$ vs $0.5 \%$; female: $15.3 \%$ vs $4.3 \%$ ) and osmotic diuresis-related AEs (5.0\% vs $2.4 \%$ ) were higher with 
A

\begin{tabular}{rrrr}
$n$ & \multicolumn{3}{c}{$\mathrm{HbA} 1 \mathrm{c}$} \\
Baseline (\%) & 371 & 391 & 387 \\
(\%) & 7.8 & 7.8 & 7.8
\end{tabular}

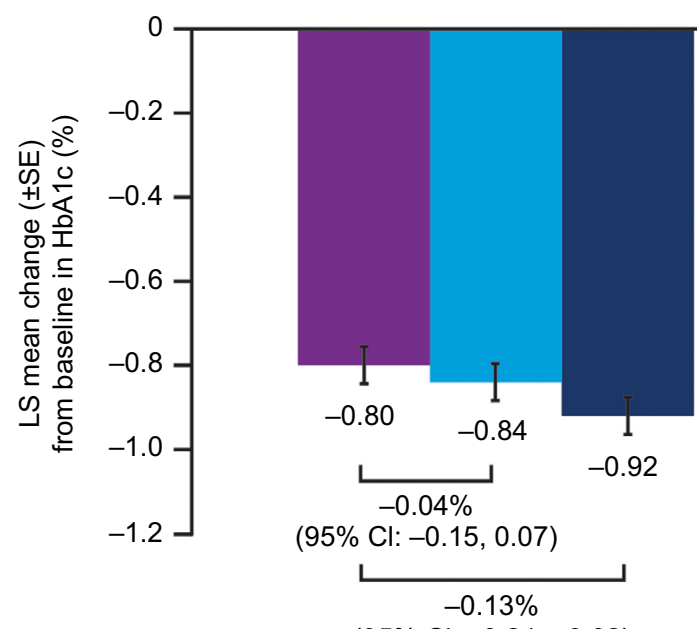

(95\% Cl: $-0.24,-0.02)$
FPG

$\begin{array}{rccc}\mathrm{n} & 375 & 390 & 388 \\ \text { Baseline }(\mathrm{mmol} / \mathrm{L}) & 9.2 & 9.3 & 9.1\end{array}$

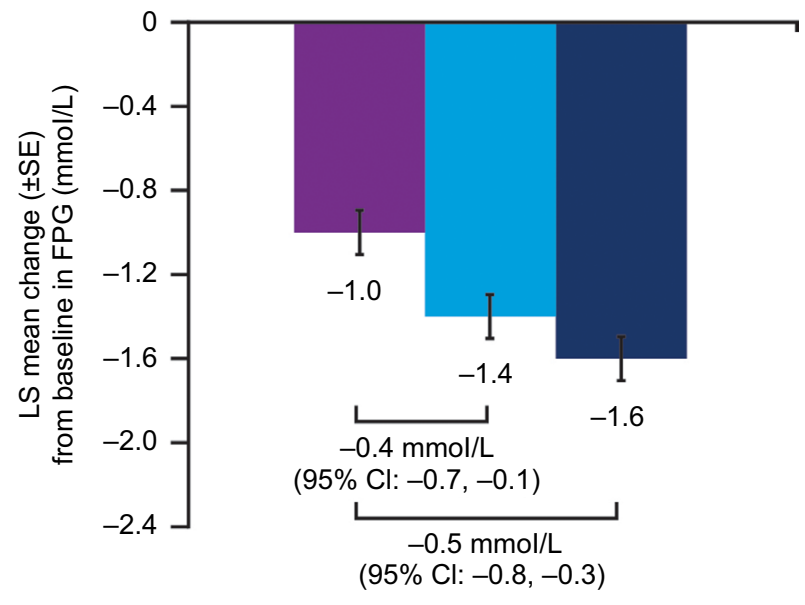

B

$\mathrm{HbA1c}$

FPG

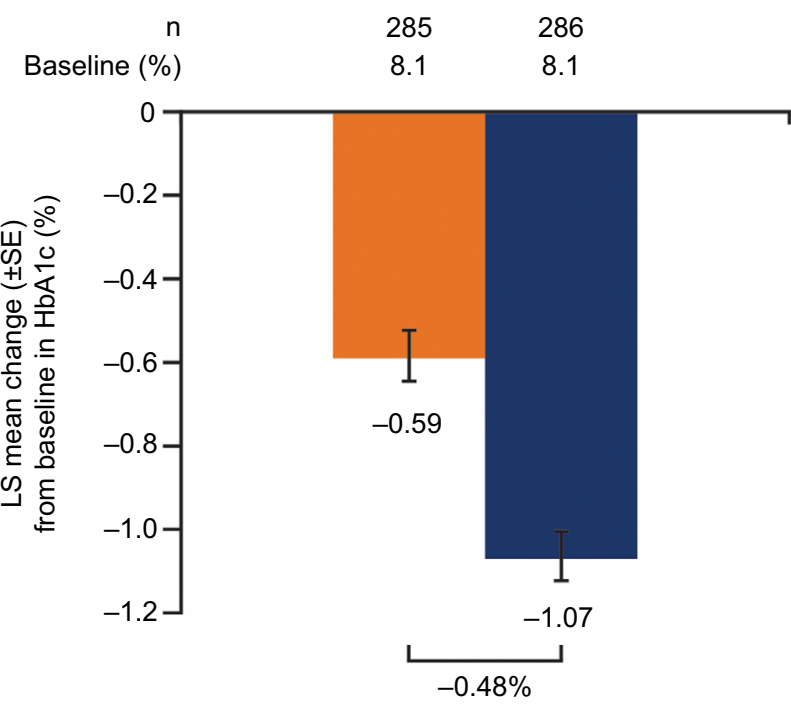

Baseline (mmol/L)

CANA $300 \mathrm{mg}$

(95\% Cl: $-0.62,-0.34)$

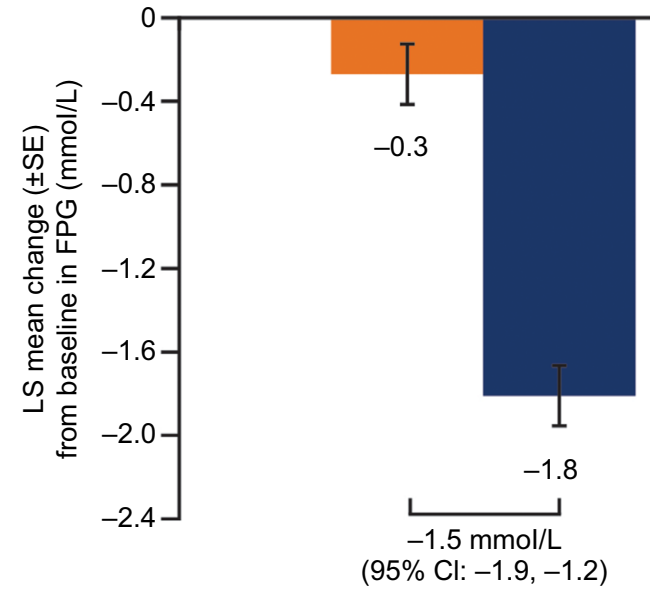

SITA 100 mg

CANA $300 \mathrm{mg}$

Figure I Effects on glycemic efficacy at week 52 in (A) study I and (B) study 2.

Abbreviations: CANA, canagliflozin; Cl, confidence interval; FPG, fasting plasma glucose; GLIM, glimepiride; LS, least squares; SE, standard error; SITA, sitagliptin.

canagliflozin $300 \mathrm{mg}$ compared with sitagliptin $100 \mathrm{mg}$, whereas the incidence of urinary tract infections was similar between groups $(4.0 \%$ vs $5.6 \%) .{ }^{22}$ When added to a background of metformin and sulfonylurea, the incidence of documented hypoglycemia was similar with canagliflozin $300 \mathrm{mg}$ and sitagliptin $100 \mathrm{mg}$ (43.2\% vs 40.7\%), despite the larger reduction in $\mathrm{HbA} 1 \mathrm{c}$ with canagliflozin in the overall study population.

\section{Discussion}

Canagliflozin improved all components of metabolic syndrome (glycemic control, BP, anthropometric measures, and dyslipidemia) in patients with T2DM and metabolic syndrome in both studies. Glycemic improvements were also seen with glimepiride and sitagliptin, albeit to a lesser extent than those seen with canagliflozin. Furthermore, neither glimepiride nor sitagliptin showed meaningful 
A

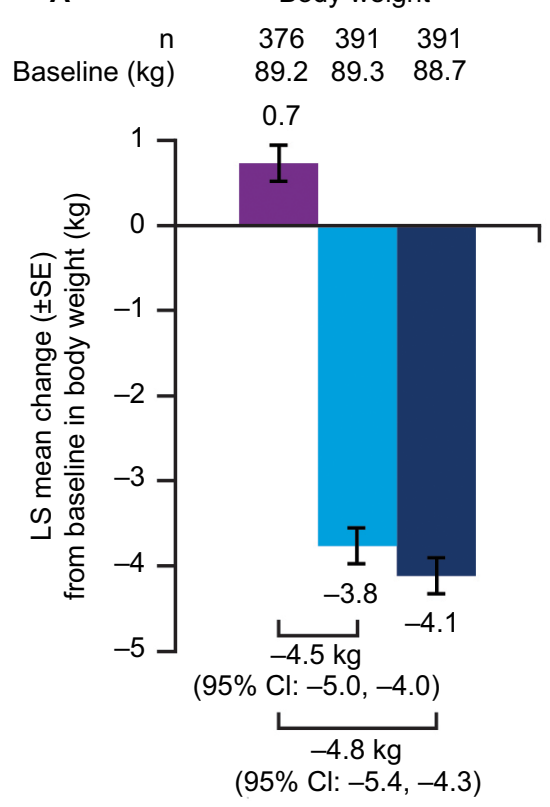

$\mathrm{BMI}$
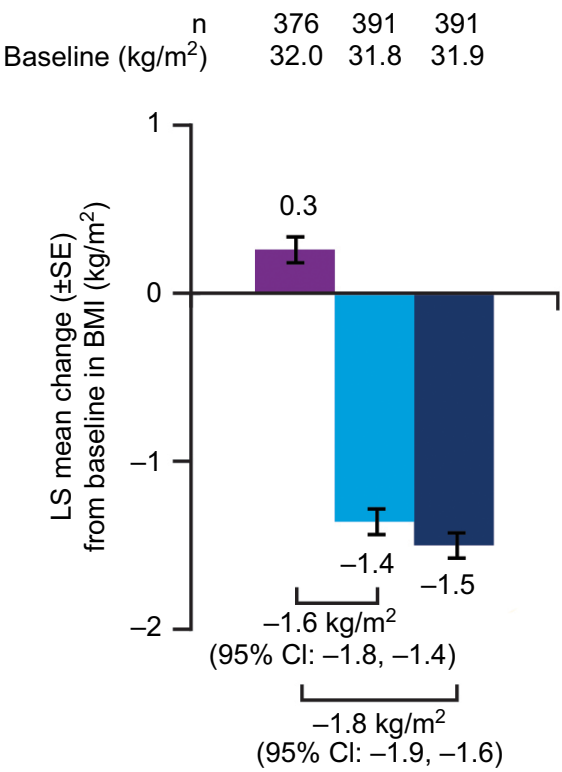

Waist circumference

$361381 \quad 376$ Baseline (cm) $\quad 105.7105 .2105 .2$

GLIM

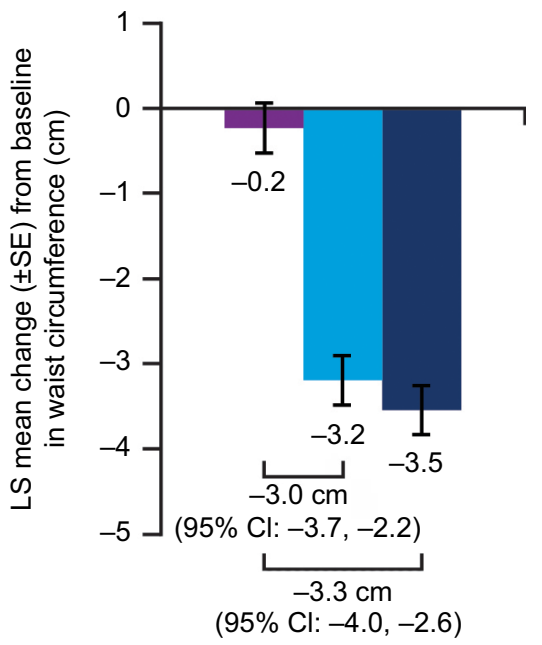

- CANA $100 \mathrm{mg}$

CANA $300 \mathrm{mg}$
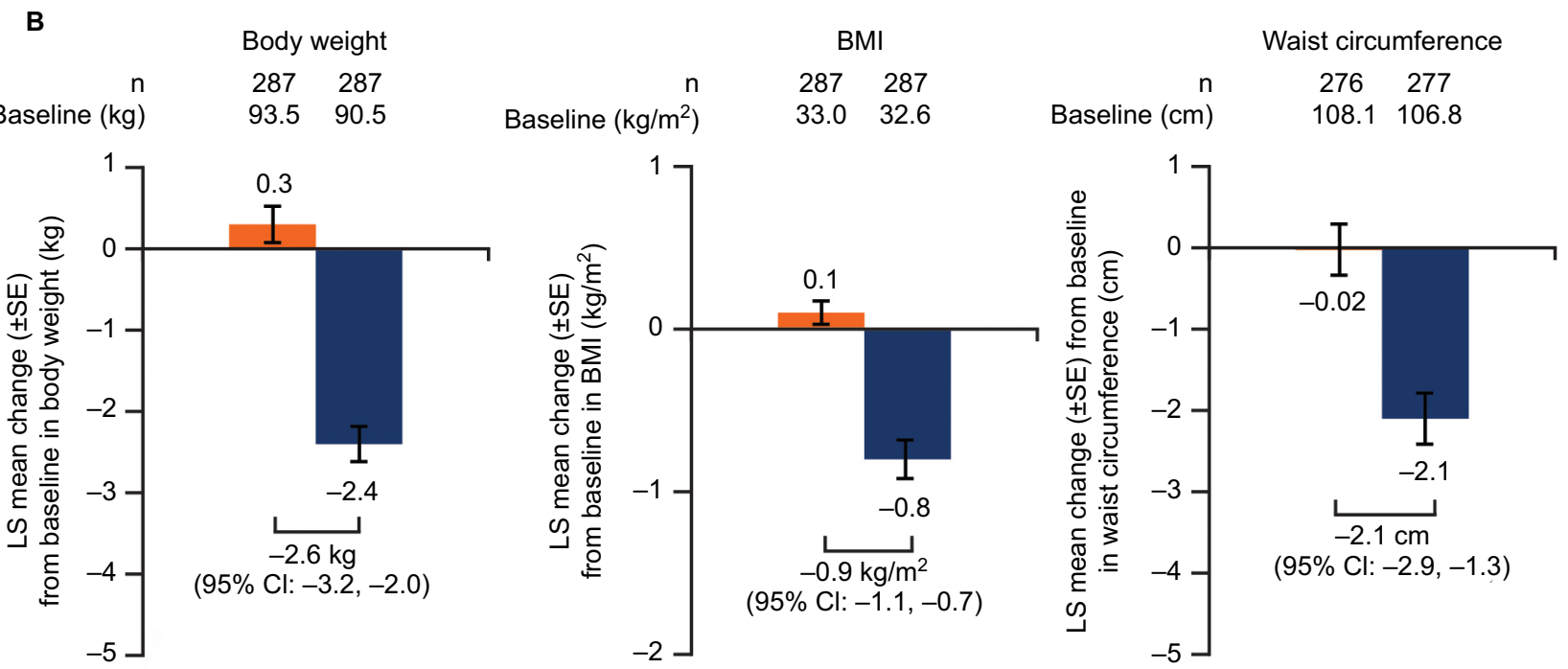

SITA $100 \mathrm{mg}$

CANA $300 \mathrm{mg}$

Figure 2 Effects on anthropometric measures at week 52 in (A) study I and (B) study 2.

Abbreviations: BMI, body mass index; CANA, canagliflozin; CI, confidence interval; GLIM, glimepiride; LS, least squares; SE, standard error; SITA, sitagliptin.

improvements in any of the other components of metabolic syndrome. Canagliflozin was generally well tolerated, with an increased incidence of AEs related to the mechanism of SGLT2 inhibition (ie, genital mycotic infections, osmotic diuresis-related AEs) in both studies.

The observed results are likely attributable to the mechanism of action for canagliflozin versus sitagliptin or glimepiride. By inhibiting SGLT2, canagliflozin increases urinary glucose excretion in an insulin-independent manner, thereby lowering plasma glucose levels and resulting in a mild osmotic diuresis and net caloric loss. ${ }^{25}$ Consequently, canagliflozin confers multiple benefits in patients with T2DM, including glycemic improvement, weight loss, and BP reduction. ${ }^{5}$ In contrast, dipeptidyl peptidase-4 inhibitors (eg, sitagliptin) have shown neutral effects on weight and BP, and sulfonylureas (eg, glimepiride) have been associated with weight gain and decreased efficacy over time. $^{26}$ 
A

$\begin{array}{rccc}\mathrm{n} & 377 & 391 & 391 \\ \text { Baseline }(\mathrm{mmHg}) & 130.9 & 131.0 & 131.3\end{array}$

Diastolic BP

$\begin{array}{lll}377 & 391 & 391 \\ 79.6 & 79.2 & 79.8\end{array}$

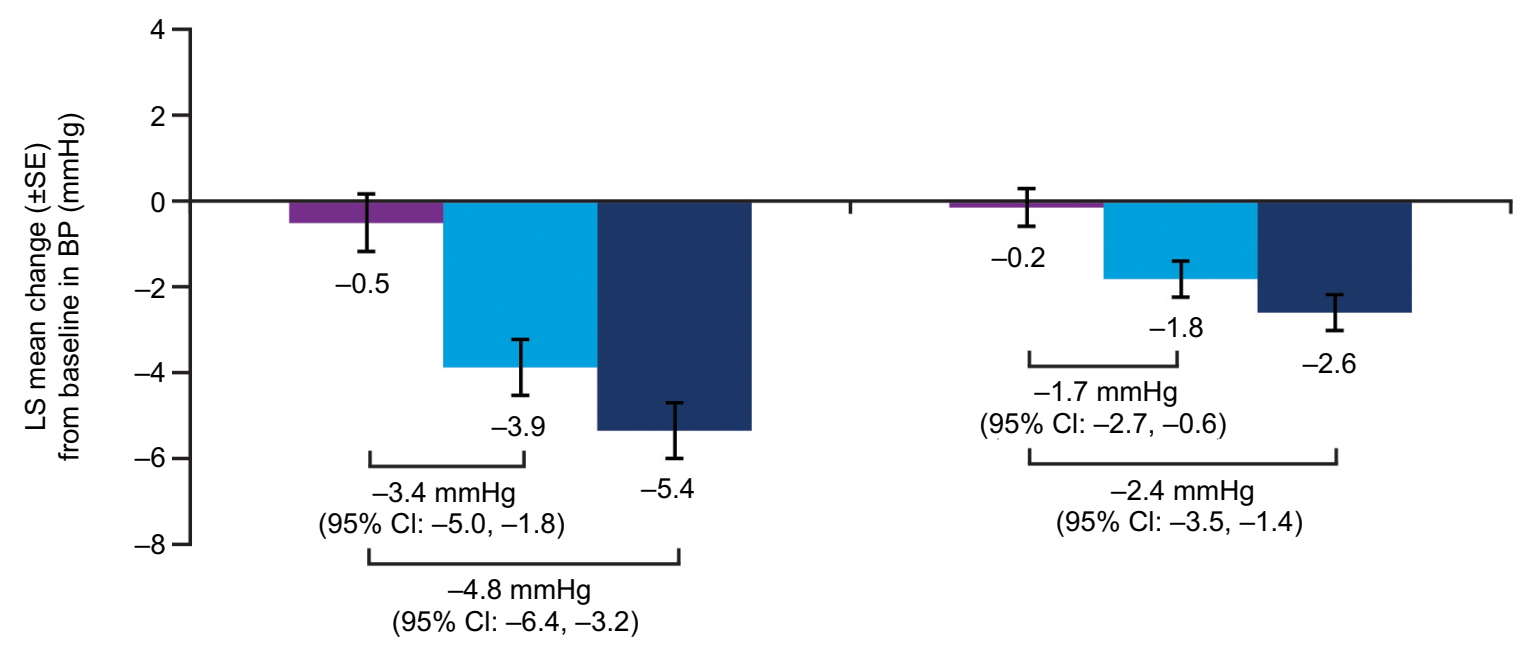

- GLIM $\quad$ CANA $100 \mathrm{mg}$ - CANA $300 \mathrm{mg}$

B

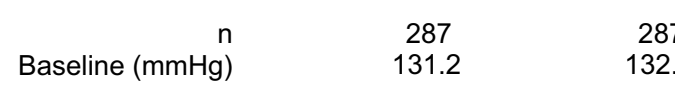

Diastolic BP

$\begin{array}{ll}287 & 287 \\ 79.2 & 80.2\end{array}$

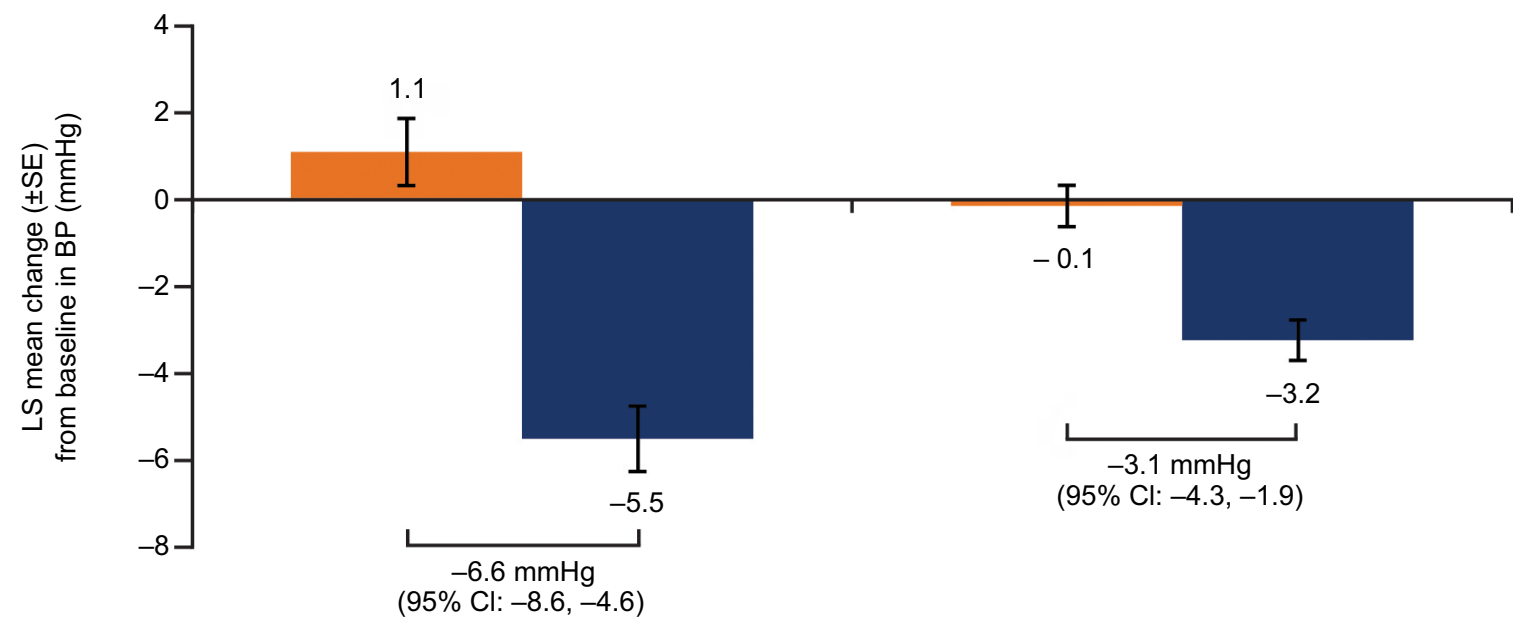

- SITA $100 \mathrm{mg} \quad$ CANA $300 \mathrm{mg}$

Figure 3 Effects on BP at week 52 in (A) study I and (B) study 2.

Abbreviations: BP, blood pressure; CANA, canagliflozin; Cl, confidence interval; GLIM, glimepiride; LS, least squares; SE, standard error; SITA, sitagliptin.

Most patients $(\sim 80 \%)$ in each study met the criteria for metabolic syndrome diagnosis at baseline. A limitation of this analysis was its post hoc nature, as patients were not randomized based on the presence of metabolic syndrome. However, baseline characteristics were generally similar across treatment groups within each study. Changes in efficacy parameters related to metabolic syndrome were generally consistent with observations from the overall population in each study. ${ }^{20,22}$ Although further analyses based on patient characteristics were not done, the efficacy and safety of canagliflozin have been shown to be generally consistent in patients with T2DM in subgroups based on baseline demographic and disease characteristics (eg, sex, age, race, ethnicity, $\mathrm{HbA} 1 \mathrm{c}$, and T2DM duration). ${ }^{27-32}$ Results from this analysis are consistent with findings from preclinical studies demonstrating the beneficial effects of treatment with other 
A

$\begin{array}{rlll}\mathrm{n} & 360 & 379 & 370 \\ \text { Baseline (mmol/L) } & 2.7 & 2.6 & 2.7\end{array}$

$0.22 \mathrm{mmol} / \mathrm{L}$

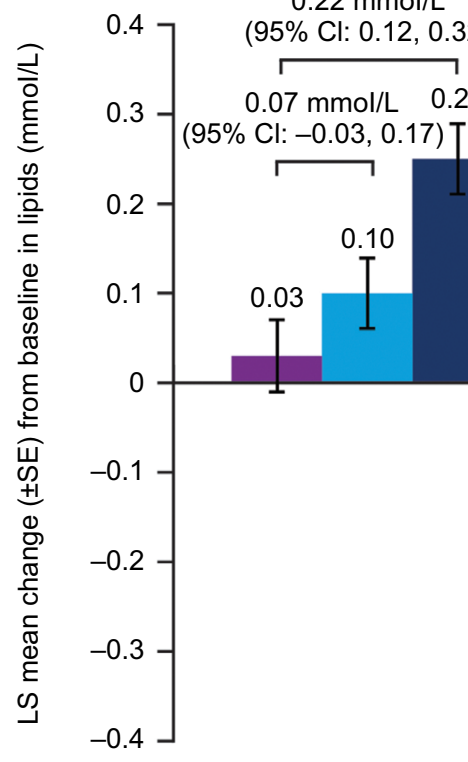

HDL-C

$\begin{array}{rrrrrr}364 & 381 & 374 & 365 & 381 & 375 \\ 1.2 & 1.2 & 1.2 & 2.1 & 2.3 & 2.3\end{array}$

$0.10 \mathrm{mmol} / \mathrm{L}$ (95\% Cl: $0.08,0.13)$

$0.08 \mathrm{mmol} / \mathrm{L}$

(95\% Cl: $0.05,0.11)$

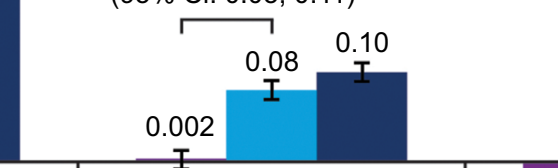

\rfloor$_{-0.04}$

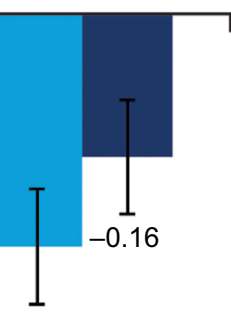

$- 0 \longdiv { 2 2 \mathrm { mmol } / \mathrm { L } }$

(95\% Cl: $-0.38,-0.06)$

$$
-0.12 \mathrm{mmol} / \mathrm{L}
$$

(95\% Cl: $-0.28,0.04)$

- GLIM $\quad$ CANA $100 \mathrm{mg} \quad$ CANA $300 \mathrm{mg}$

B

LDL-C

HDL-C

Triglycerides

$\begin{array}{rrr}\mathrm{n} & 273 & 276 \\ \text { Baseline }(\mathrm{mmol} / \mathrm{L}) & 2.5 & 2.6\end{array}$

$274 \quad 277$

$274 \quad 278$

$1.1 \quad 1.1$

$2.1 \quad 2.3$

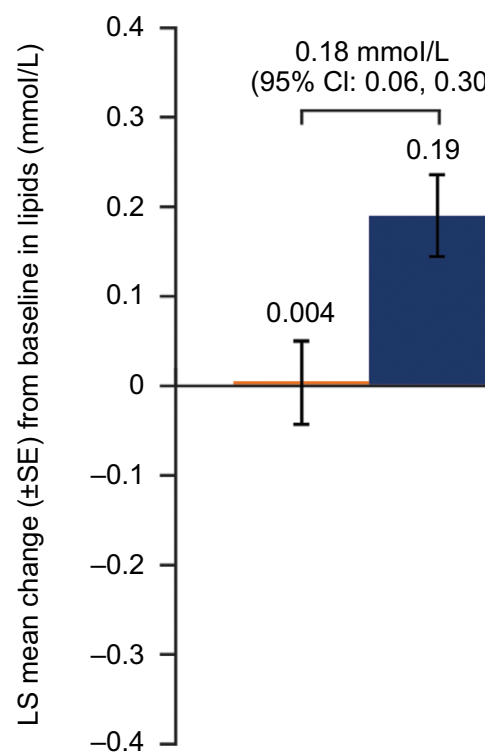

$0.07 \mathrm{mmol} / \mathrm{L}$ (95\% Cl: $0.04,0.10)$

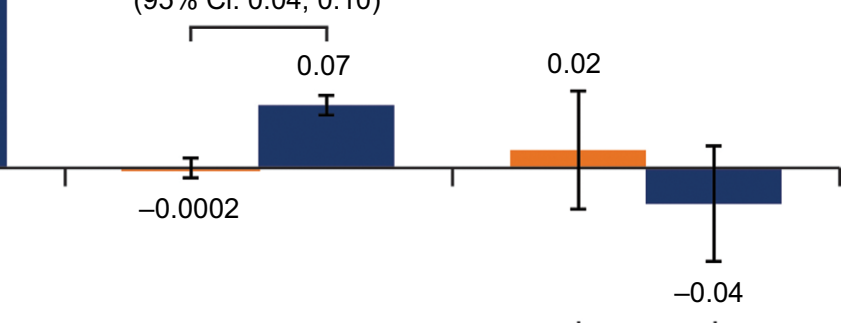

$-0.07 \mathrm{mmol} / \mathrm{L}$

(95\% Cl: $-0.24,0.10)$

Figure 4 Effects on fasting plasma lipids at week 52 in (A) study I and (B) study 2

Abbreviations: CANA, canagliflozin; Cl, confidence interval; GLIM, glimepiride; HDL-C, high-density lipoprotein cholesterol; LDL-C, low-density lipoprotein cholesterol; LS, least squares; SE, standard error; SITA, sitagliptin. 
SGLT2 inhibitors in the setting of metabolic syndrome. ${ }^{33-35}$ Despite these beneficial effects on all components of metabolic syndrome, there were small changes in the proportion of patients meeting the criteria for metabolic syndrome at week 52 in both studies. This is likely due to the continued diagnosis and treatment of T2DM, hypertension, and dyslipidemia following treatment in these studies. Furthermore, the present studies were not designed to ascertain the regression of metabolic syndrome.

The multifactorial nature of metabolic syndrome makes it a challenging condition to manage using currently available therapeutic agents. ${ }^{36}$ Because canagliflozin has positive effects on multiple parameters (eg, glycemic, body weight, BP), it may be particularly beneficial for patients with metabolic syndrome and ultimately contribute to a decreased risk of cardiovascular disease. Results from the EMPA-REG OUTCOME trial have demonstrated reductions in cardiovascular risk in patients with T2DM treated with the SGLT2 inhibitor empagliflozin. ${ }^{37}$ The potential benefits of canagliflozin on cardiometabolic outcomes are currently being assessed in the CANagliflozin cardioVascular Assessment Study (CANVAS) program, which consists of 2 ongoing trials in patients with T2DM and a history or high risk of cardiovascular disease (ie, CANVAS [ClinicalTrials.gov identifier: NCT01032629] and CANVAS-R [renal endpoints; ClinicalTrials.gov identifier: NCT01989754]).

\section{Conclusion}

These findings demonstrate that canagliflozin has beneficial effects on the multiple components of metabolic syndrome compared with glimepiride or sitagliptin in patients with T2DM and metabolic syndrome.

\section{Acknowledgments}

This analysis was funded by Janssen Scientific Affairs, LLC. Medical writing support was provided by Alaina Mitsch, $\mathrm{PhD}$, of MedErgy, and was funded by Janssen Global Services, LLC.

Canagliflozin has been developed by Janssen Research \& Development, LLC, in collaboration with Mitsubishi Tanabe Pharma Corporation.

\section{Disclosure}

MJD and KWM are full-time employees of Janssen Scientific Affairs, LLC. UV, DAB, and MD are full-time employees of Janssen Research \& Development, LLC. The authors report no other conflicts of interest in this work.

\section{References}

1. Eckel RH, Grundy SM, Zimmet PZ. The metabolic syndrome. Lancet. 2005;365(9468):1415-1428.

2. O'Neill S, O'Driscoll L. Metabolic syndrome: a closer look at the growing epidemic and its associated pathologies. Obes Rev. 2015;16(1):1-12.

3. Aguilar M, Bhuket T, Torres S, Liu B, Wong RJ. Prevalence of the metabolic syndrome in the United States, 2003-2012. JAMA. 2015; 313(19):1973-1974.

4. van Vliet-Ostaptchouk JV, Nuotio ML, Slagter SN, et al. The prevalence of metabolic syndrome and metabolically healthy obesity in Europe: a collaborative analysis of ten large cohort studies. BMC Endocr Disord. 2014;14:9.

5. Rosenthal N, Meininger G, Ways K, et al. Canagliflozin: a sodium glucose co-transporter 2 inhibitor for the treatment of type 2 diabetes mellitus. Ann NY Acad Sci. 2015;1358(1):28-43.

6. Stenlöf K, Cefalu WT, Kim KA, et al. Efficacy and safety of canagliflozin monotherapy in subjects with type 2 diabetes mellitus inadequately controlled with diet and exercise. Diabetes Obes Metab. 2013;15(4):372-382.

7. Stenlöf K, Cefalu WT, Kim KA, et al. Long-term efficacy and safety of canagliflozin monotherapy in patients with type 2 diabetes inadequately controlled with diet and exercise: findings from the 52-week CANTATAM study. Curr Med Res Opin. 2014;30(2):163-175.

8. Lavalle-González FJ, Januszewicz A, Davidson J, et al. Efficacy and safety of canagliflozin compared with placebo and sitagliptin in patients with type 2 diabetes on background metformin monotherapy: a randomised trial. Diabetologia. 2013;56(12):2582-2592.

9. Wilding JP, Charpentier G, Hollander P, et al. Efficacy and safety of canagliflozin in patients with type 2 diabetes mellitus inadequately controlled with metformin and sulphonylurea: a randomised trial. Int J Clin Pract. 2013;67(12):1267-1282.

10. Forst T, Guthrie R, Goldenberg R, et al. Efficacy and safety of canagliflozin over 52 weeks in patients with type 2 diabetes on background metformin and pioglitazone. Diabetes Obes Metab. 2014; 16(5):467-477.

11. Neal B, Perkovic V, de Zeeuw D, et al. Efficacy and safety of canagliflozin, an inhibitor of sodium glucose co-transporter 2, when used in conjunction with insulin therapy in patients with type 2 diabetes. Diabetes Care. 2015;38(3):403-411.

12. Fulcher G, Matthews DR, Perkovic V, et al. Efficacy and safety of canagliflozin used in conjunction with sulfonylurea in patients with type 2 diabetes mellitus: a randomized, controlled trial. Diabetes Ther. 2015;6(3):289-302.

13. Fulcher G, Matthews DR, Perkovic V, et al. Efficacy and safety of canagliflozin when used in conjunction with incretin-mimetic therapy in patients with type 2 diabetes. Diabetes Obes Metab. 2016;18(1):82-91.

14. Rosenstock J, Chuck L, Gonzalez-Ortiz M, Merton K, Craig J, Capuano G. Initial combination therapy with canagliflozin plus metformin versus each component as monotherapy in drug-naive type 2 diabetes. Diabetes Care. 2016;39(3):353-362.

15. Rodbard HW, Seufert J, Aggarwal N, et al. Efficacy and safety of titrated canagliflozin in patients with type 2 diabetes mellitus inadequately controlled on metformin and sitagliptin. Diabetes Obes Metab. 2016;18(8):812-819.

16. Yale JF, Bakris G, Cariou B, et al. Efficacy and safety of canagliflozin in subjects with type 2 diabetes and chronic kidney disease. Diabetes Obes Metab. 2013;15(5):463-473.

17. Yale JF, Bakris G, Cariou B, et al. Efficacy and safety of canagliflozin over 52 weeks in patients with type 2 diabetes mellitus and chronic kidney disease. Diabetes Obes Metab. 2014;16(10):1016-1027.

18. Bode B, Stenlöf K, Sullivan D, Fung A, Usiskin K. Efficacy and safety of canagliflozin treatment in older subjects with type 2 diabetes mellitus: a randomized trial. Hosp Pract. 2013;41(2):72-84.

19. Bode B, Stenlöf K, Harris S, et al. Long-term efficacy and safety of canagliflozin over 104 weeks in patients aged 55-80 years with type 2 diabetes. Diabetes Obes Metab. 2015;17(3):294-303. 
20. Cefalu WT, Leiter LA, Yoon KH, et al. Efficacy and safety of canagliflozin versus glimepiride in patients with type 2 diabetes inadequately controlled with metformin (CANTATA-SU): 52 week results from a randomised, double-blind, phase 3 non-inferiority trial. Lancet. 2013; 382(9896):941-950.

21. Leiter LA, Yoon KH, Arias P, et al. Canagliflozin provides durable glycemic improvements and body weight reduction over 104 weeks versus glimepiride in patients with type 2 diabetes on metformin: a randomized, double-blind, phase 3 study. Diabetes Care. 2015;38(3): 355-364.

22. Schernthaner G, Gross JL, Rosenstock J, et al. Canagliflozin compared with sitagliptin for patients with type 2 diabetes who do not have adequate glycemic control with metformin plus sulfonylurea: a 52-week, randomized trial. Diabetes Care. 2013;36(9):2508-2515.

23. Ji L, Han P, Liu Y, et al. Canagliflozin in Asian patients with type 2 diabetes on metformin alone or metformin in combination with sulphonylurea. Diabetes Obes Metab. 2015;17(1):23-31.

24. Lavalle-González FJ, Eliaschewitz FG, Cerdas S, Del Pilar CM, Tong C, Alba M. Efficacy and safety of canagliflozin in patients with type 2 diabetes mellitus from Latin America. Curr Med Res Opin. 2016; 32(3):427-439.

25. Mudaliar S, Polidori D, Zambrowicz B, Henry RR. Sodium-glucose cotransporter inhibitors: effects on renal and intestinal glucose transport: from bench to bedside. Diabetes Care. 2015;38(12):2344-2353.

26. Inzucchi SE, Bergenstal RM, Buse JB, et al. Management of hyperglycemia in type 2 diabetes, 2015: a patient-centered approach: update to a position statement of the American Diabetes Association and the European Association for the Study of Diabetes. Diabetes Care. 2015; 38(1):140-149.

27. Sinclair A, Bode B, Harris S, et al. Efficacy and safety of canagliflozin compared with placebo in older patients with type 2 diabetes mellitus: a pooled analysis of clinical studies. BMC Endocr Disord. 2014; 14(1):37.
28. Sinclair AJ, Bode B, Harris S, et al. Efficacy and safety of canagliflozin in individuals aged 75 and older with type 2 diabetes mellitus: a pooled analysis. J Am Geriatr Soc. 2016;64(3):543-552.

29. Gilbert RE, Weir MW, Fioretto P, et al. Impact of age and estimated glomerular filtration rate on the glycaemic efficacy and safety of canagliflozin: a pooled analysis of clinical studies. Can J Diabetes. 2016;40(3): $247-257$.

30. Gavin JR 3rd, Davies MJ, Davies M, Vijapurkar U, Alba M, Meininger G. The efficacy and safety of canagliflozin across racial groups in patients with type 2 diabetes mellitus. Curr Med Res Opin. 2015;31(9):1693-1702.

31. Davidson JA, Aguilar R, Lavalle González FJ, et al. Efficacy and safety of canagliflozin in type 2 diabetes patients of different ethnicity. Ethn Dis. 2016;26(2):221-228.

32. Wilding JPH, Blonde L, Leiter LA, et al. Efficacy and safety of canagliflozin by baseline HbA1c and known duration of type 2 diabetes mellitus. J Diabetes Complications. 2015;29(3):438-444.

33. Rahman A, Kittikulsuth W, Fujisawa Y, et al. Effects of diuretics on sodium-dependent glucose cotransporter 2 inhibitor-induced changes in blood pressure in obese rats suffering from the metabolic syndrome. J Hypertens. 2016;34(5):893-906.

34. Tahara A, Kurosaki E, Yokono M, et al. Effects of SGLT2 selective inhibitor ipragliflozin on hyperglycemia, hyperlipidemia, hepatic steatosis, oxidative stress, inflammation, and obesity in type 2 diabetic mice. Eur J Pharmacol. 2013;715(1-3):246-255.

35. Thomas L, Grempler R, Eckhardt M, et al. Long-term treatment with empagliflozin, a novel, potent and selective SGLT-2 inhibitor, improves glycaemic control and features of metabolic syndrome in diabetic rats. Diabetes Obes Metab. 2012;14(1):94-96.

36. Matfin G. Challenges in developing therapies for the metabolic syndrome. Br J Diabetes Vasc Dis. 2007;7(4):152-156.

37. Zinman B, Wanner C, Lachin JM, et al. Empagliflozin, cardiovascular outcomes, and mortality in type 2 diabetes. $N$ Engl J Med. 2015 $373(22): 2117-2128$

Diabetes, Metabolic Syndrome and Obesity: Targets and Therapy

Dovepress

\section{Publish your work in this journal}

Diabetes, Metabolic Syndrome and Obesity: Targets and Therapy is an international, peer-reviewed open-access journal committed to the rapid publication of the latest laboratory and clinical findings in the fields of diabetes, metabolic syndrome and obesity research Original research, review, case reports, hypothesis formation, expert opinion and commentaries are all considered for publication. The manuscript management system is completely online and includes a very quick and fair peer-review system, which is all easy to use. Visit http://www.dovepress.com/testimonials.php to read real quotes from published authors. 